\title{
A Bayesian Network-Based Browsing Model for Patients Seeking Radiology-Related Information on Hospital Websites: Development and Usability Study
}

Ryusuke Suzuki ${ }^{1}$, MHS; Teppei Suzuki ${ }^{1,2}$, MBA, PhD; Shintaro Tsuji ${ }^{1}$, PhD; Kensuke Fujiwara ${ }^{1,3}$, PhD, MBA; Hiroko

Yamashina ${ }^{1}, \mathrm{PhD}$; Akira Endoh ${ }^{4}, \mathrm{PhD}$; Katsuhiko Ogasawara ${ }^{1,4}, \mathrm{MBA}, \mathrm{PhD}$

${ }^{1}$ Graduate School of Health Sciences, Hokkaido University, Sapporo, Japan

${ }^{2}$ Iwamizawa Campus, Hokkaido University of Education, Iwamizawa, Japan

${ }^{3}$ Graduate School of Commerce, Otaru University of Commerce, Otaru, Japan

${ }^{4}$ Department of Medical Informatics, Hokkaido University Hospital, Sapporo, Japan

\section{Corresponding Author:}

Katsuhiko Ogasawara, MBA, PhD

Graduate School of Health Sciences

Hokkaido University

N12-W5, Kita-ku

Sapporo

Japan

Phone: 81117063409

Email: oga@hs.hokudai.ac.jp

\section{Abstract}

Background: An increasing number of people are visiting hospital websites to seek better services and treatments compared to the past. It is therefore important for hospitals to develop websites to meet the needs of their patients. However, few studies have investigated whether and how the current hospital websites meet the patient's needs. Above all, in radiation departments, it may be difficult for patients to obtain the desired information regarding modality and diagnosis because such information is subdivided when described on a website.

Objective: The purpose of this study is to suggest a hospital website search behavior model by analyzing the browsing behavior model using a Bayesian network from the perspective of one-to-one marketing.

Methods: First, we followed the website access log of Hokkaido University Hospital, which was collected from September 1, 2016, to August 31, 2017, and analyzed the access log using Google Analytics. Second, we specified the access records related to radiology from visitor browsing pages and keywords. Third, using these resources, we structured 3 Bayesian network models based on specific patient needs: radiotherapy, nuclear medicine examination, and radiological diagnosis. Analyzing each model, this study considered why some visitors could not reach their desired page and improvements to meet the needs of visitors seeking radiology-related information.

Results: The radiotherapy model showed that $74 \%$ (67/90) of the target visitors could reach their requested page, but only $2 \%$ (2/90) could reach the Center page where inspection information, one of their requested pages, is posted. By analyzing the behavior of the visitors, we clarified that connecting with the radiotherapy and radiological diagnosis pages is useful for increasing the proportion of patients reaching their requested page.

Conclusions: We proposed solutions for patient web-browsing accessibility based on a Bayesian network. Further analysis is necessary to verify the accuracy of the proposed model in comparison to other models. It is expected that information provided on hospital websites will be improved using this method.

(J Med Internet Res 2021;23(1):e14794) doi: 10.2196/14794

\section{KEYWORDS}

web marketing; internet; hospitals; radiology; information-seeking behavior 


\section{Introduction}

\section{Hospital Web Marketing in Japan}

For patients to choose a preferred hospital, information transmission using a hospital website is important because the external environment is constantly changing, owing to improvements to the internet and new competitive relationships as a result of the declining trend of patients [1,2]. It is assumed that there are 2 major reasons why information on websites has become increasingly important for hospital management. First, patients can choose a hospital based on their personal preferences. The "paternalism model," where physicians make decisions, was previously the mainstream; however, patients have shifted to an "informed decision model," where they make decisions themselves [3]. A previous study conducted by the Japanese Ministry of Health, Labor, and Welfare revealed that the percentage of those who responded that "I have obtained information" for the item "Is information usually obtained when you visit the hospital?" increased by 30\% compared to 2011 [4]. Second, the popularization of smartphones among all age groups has led to significant lifestyle changes [5,6]. Patients can select a hospital based on the information available on a website. According to the National Federation of Health Insurance Societies [7], the information from a hospital website has the largest impact on hospital selection. The internet serves as an important source of medical information [8]. A study showed that "hospital websites" and "information websites about hospitals" account for a high proportion of the available credible information.

In previous research targeting hospitals in Japan, the introduction of marketing departments in hospitals has recently been proposed [9]. However, medical advertising guidelines make it difficult for hospitals to advertise as a company [10]. In today's society, with advances in the internet, it is expected that the proportion of individuals who choose to seek information from such sources when deciding on a hospital for an examination or treatment will continue to increase, despite the strict regulations. Therefore, hospitals need their own web marketing methods.

\section{Improve Information Provision on Hospital Websites}

Through recent marketing, CRM, one-to-one marketing, and personalization aimed at increasing patient satisfaction and loyalty by reaching individual consumers through the spread of the internet and intensified competition are attracting attention $[11,12]$. It is therefore desirable to transmit appropriate information to the websites according to the needs of each visitor. For this reason, to improve information provisioning on websites, it is common to analyze the current state of websites using quantitative data such as access logs. As advertising regulations were adopted on websites in Japan, the study focused on whether the information posted on websites followed the regulations [13,14]. In the United States, there are weaker advertising regulations on websites than Japan; a study evaluated the accessibility of websites to provide high-fidelity information from the viewpoint of public health [15]. Few have focused on the browsing behaviors of visitors on hospital websites. Suzuki et al [16] attempted to develop a method for creating browsing behavior models and assessing the intentions of patients on hospital websites. However, no models have been proposed that allow medical staff to intuitively understand the browsing behavior of patients and propose improvements to meet the needs of visitors seeking radiology-related information. Therefore, we focused on a Bayesian network that can easily understand variable relationships.

Owing to the market trends, we decided to analyze not all visitors but specific visitors. Our research target, Hokkaido University Hospital, is one of the largest hospitals in Japan with 944 beds. Furthermore, Hokkaido University Hospital has one of the 17 proton therapy facilities in the country and therefore provides advanced medical care in the field of radiotherapy [17]. It is possible that there was a certain need at this hospital to provide information in response to citizen requests for the transmission of radiology-related information. In addition, after the Great East Japan Earthquake (March 11, 2011), several individuals have become interested in radiology-related information. Some studies have reported that few people have sufficient knowledge of radiology, and many people are concerned about exposure to radiation $[18,19]$. Owing to these situations, several patients have sought information on the safety and effects of radiotherapy and radiological diagnosis. Furthermore, there are various types of radiological diagnoses, such as radiography, computed tomography, and magnetic resonance imaging, which make it difficult for patients to understand each type of examination. This study conducted a behavioral analysis focusing on visitors seeking radiology-related information.

The purpose of this study is to propose a hospital website search behavior model in which medical staff can easily understand the browsing scenario by analyzing the browsing behavior of visitors who are looking for radiology-related information based on the results of a Bayesian network from the perspective of one-to-one marketing.

\section{Methods}

\section{Scheme}

A flowchart of our research is shown in Figure 1. The page that we believe the target wants to browse was defined as the "request page (RP)." In addition, a target reaching the requested page was defined as a "conversion," and the ratio of conversion as the "conversion rate (CVR)," as shown in $C V R(\%)=\frac{\text { Session Number Viewing RP(Request Page) }}{\text { Target Session Number }}$. We attempted to enhance the CVR using a Bayesian network with an access log. We used the website data access log of the Hokkaido University Hospital website (Figures 2 and 3), which has 208 pages. Our research focused on the patients seeking radiology-related information at Hokkaido University Hospital as the target visitors. 
Figure 1. Research scheme.

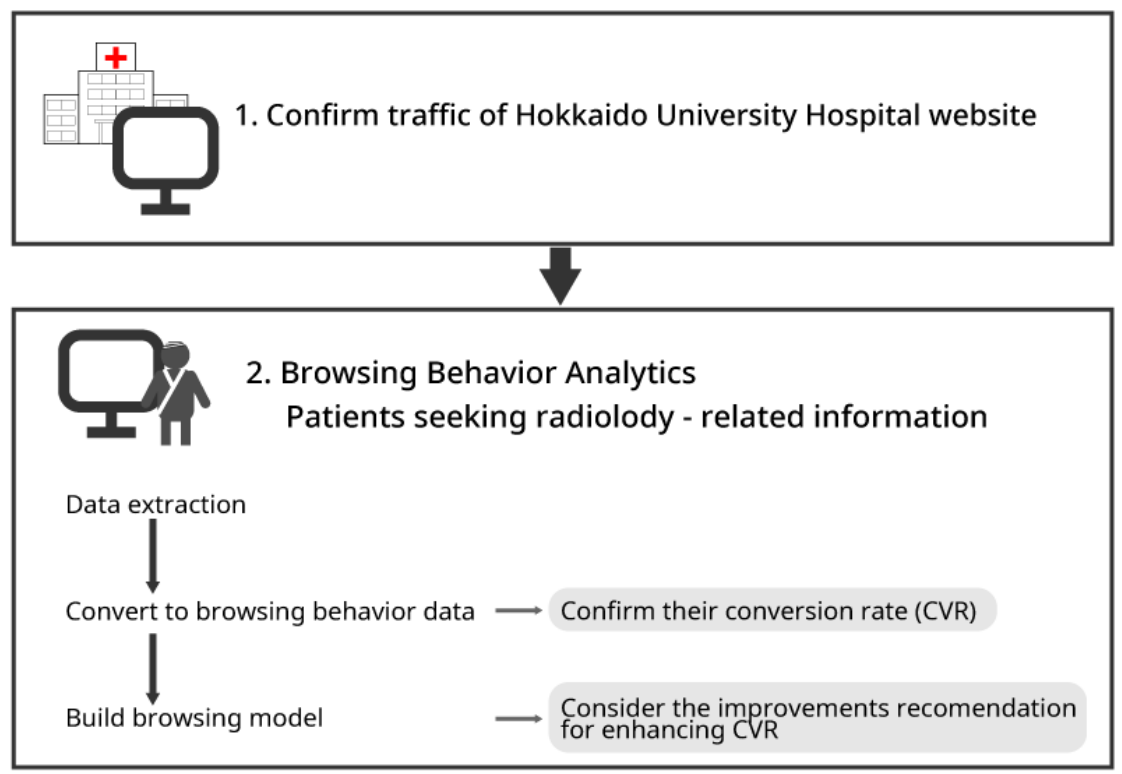

Figure 2. Abstract of target website link about radiology-related information. PRT-CT: positron emission tomography-computed tomography; RI: radio isotope.

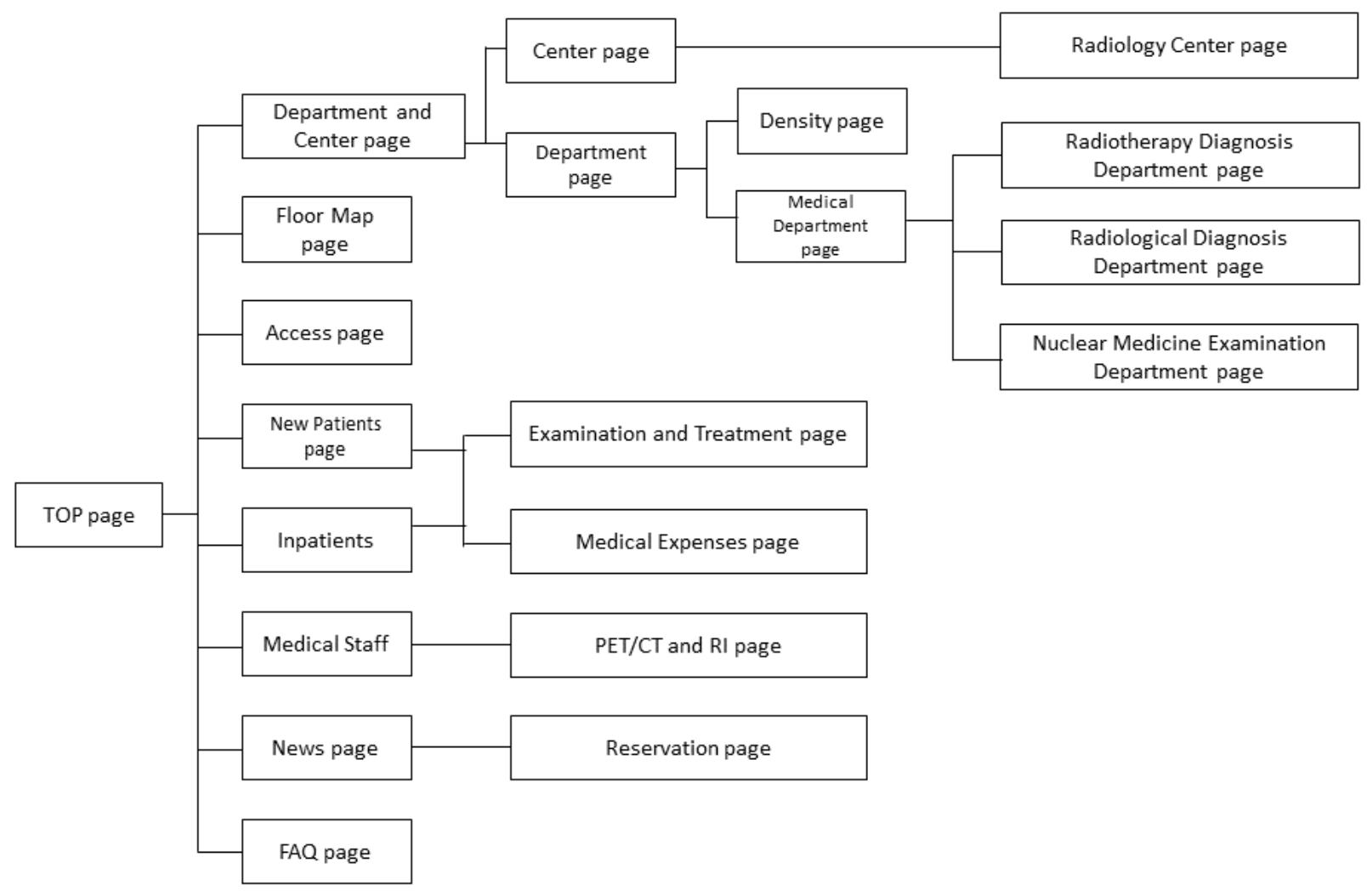


Figure 3. TOP page of Hokkaido University Hospital website (personal computer edition).

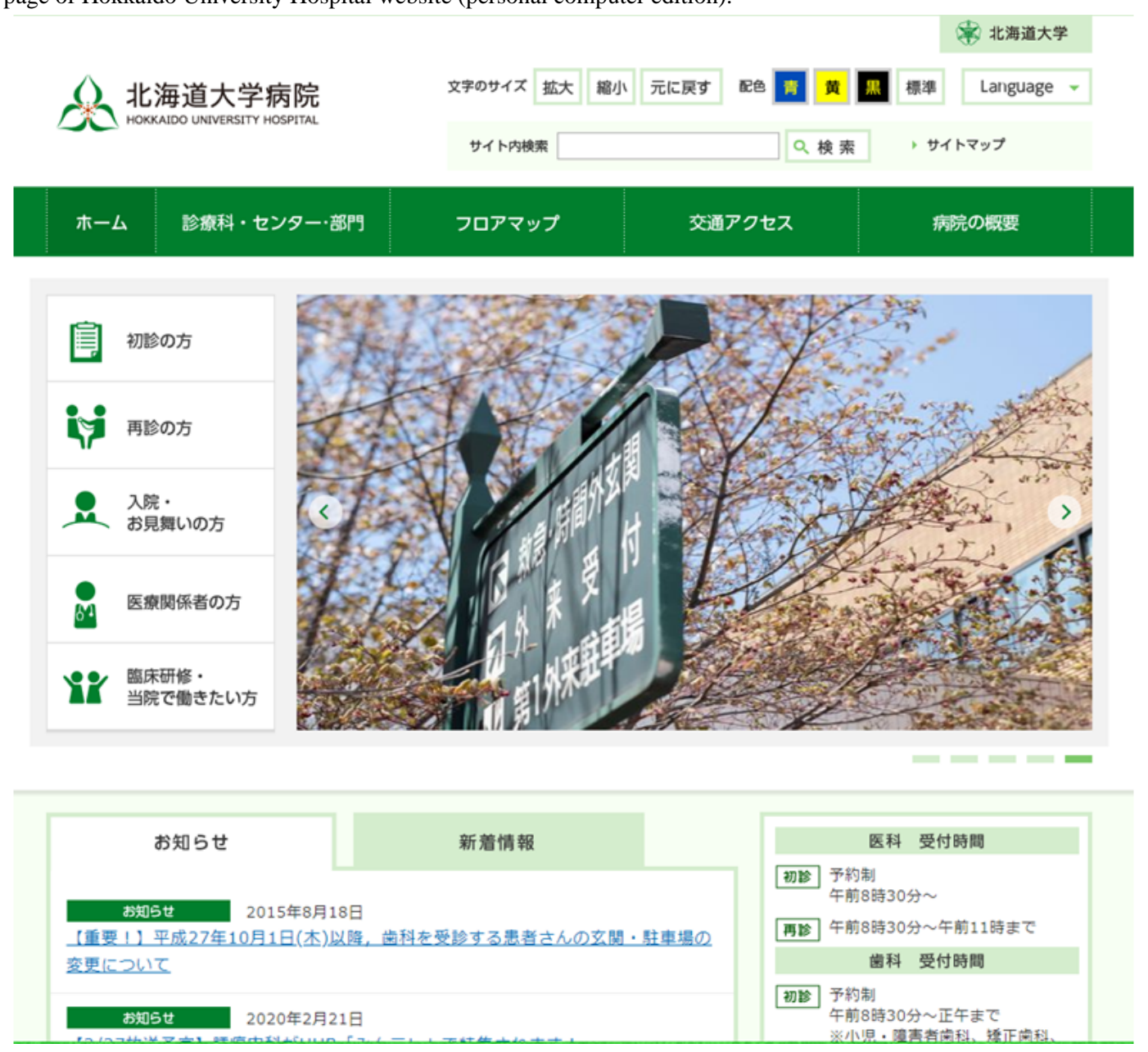

\section{Traffic Confirmation}

First, we collected the website access log of Hokkaido University Hospital from September 1, 2016, to August 31, 2017. Knowing the purpose and needs of the visitors is useful for improving a website; however, this information usually cannot be observed, and it is necessary to understand this information through an analysis of the data access log. This research analyzed the access log using Google Analytics. Google Analytics is a tool that allows users to visualize the access status without a server that even medical clerks can easily handle. Google Analytics has been widely used in public institutions, including hospitals $[16,20]$. We used "page view," which shows the number of pages viewed by visitors, "session," which shows the number of times any visitor accessed the website, and "page depth," which shows the number of pages viewed in a single session.

\section{Data Extraction}

First, we acquired data from the access log by designating 8 indicators using Analytics Edge, which is an add-in service of Google Analytics. The following metrics were collected from the user's http request: 1 , page title; 2 , retrieval keyword by visitor; 3 , municipalities of visitors; 4 , browsing date by visitor; 5 , network domain of the visitor; 6 , page depth; 7 , operation system of the visitor; and 8, page views. Although Google Analytics issues a "Client ID," which identifies the user, the website administrator cannot obtain the ID. Thus, the administrator cannot identify the individual user data from the raw data. Therefore, the behavior data of each user was identified by generating a pseudo user ID from indicators 2 to 7 , which led to the identification of the user. We used only indicators 3 to 7 to identify the user. We extracted data for 870 sessions using 32 radiology-related keywords that the target would use as a retrieval keyword, as shown in Multimedia Appendix 1. This selection was made by a specialist in the field of radiology. The exclusion conditions in the data extraction used were as follows: we excluded the records of the session with a page depth of 1 because of the difficulty in interpreting the intention to visit [21]. To acquire patient data, we excluded the following types of data used in retrieval keywords: recruitment-related words (eg, touring and recruitment), technical terms (eg, academic society and doctor names), and words related to needs other than treatment and examination. We also excluded data with ".ac.jp" at the end of the network domain, which is called the second-level domain.

Second, we classified the extracted sessions into 3 types of needs using retrieval keywords: 1, sought radiotherapy information; 2, sought information on nuclear medicine examination; and 3 , sought information on radiological diagnosis. The judgment of the 3 classifications was based on an interpretation of indicator 1: retrieval keywords by a specialist in radiology. 
Third, the RP for the 3 groups were selected, as shown in Table 1. However, the RP was an estimate because we could not know for certain what information was needed. Thus, we chose the RP in order of high scores for "Explanation of flow of examination," "Request/notes," "Explanation of technical terms," and "Explanation of equipment" in reference to the previous study, for the 3 groups from the target website [22]. Table 2 shows the evaluation criteria. The Center Navigation page, that is, the link source of the Radiology Center page, was set as RP1. Because the Radiology page was an external link, we could not examine the access log.

Table 1. Request pages in each model.

\begin{tabular}{lllll}
\hline Group & Request pages & & \\
& 1 & 2 & 3 & 4 \\
\hline Radiotherapy & $\begin{array}{l}\text { Center Naviga- } \\
\text { tion }\end{array}$ & Radiotherapy Department & a $^{\mathrm{a}}$ & \\
$\begin{array}{l}\text { Nuclear medicine examina- } \\
\text { tion }\end{array}$ & $\begin{array}{l}\text { Center Naviga- } \\
\text { tion }\end{array}$ & $\begin{array}{l}\text { Nuclear Medicine Examination Depart- } \\
\text { ment }\end{array}$ & $\begin{array}{l}\text { Examination and Treat- } \\
\text { ment }\end{array}$ & $\begin{array}{l}\text { PRT-CT }^{\mathrm{b}} \text { and Nuclear } \\
\text { Medicine }\end{array}$ \\
Radiological diagnosis & $\begin{array}{l}\text { Center Naviga- } \\
\text { tion }\end{array}$ & Radiological Diagnosis Department & $\begin{array}{l}\text { Examination and Treat- } \\
\text { ment }\end{array}$ & - \\
\hline
\end{tabular}

${ }^{\mathrm{a}}$ The request pages (RPs) for 3 groups were set by a specialist in radiology. The lower rank RP in a certain group was not applicable in our RP selection. ${ }^{\mathrm{b}}$ PRT-CT: positron emission tomography-computed tomography.

Table 2. Criterion for page evaluation.

\begin{tabular}{|c|c|}
\hline Assessment and condition & Score \\
\hline \multicolumn{2}{|l|}{ Equipment description } \\
\hline Statement & 2 \\
\hline No statement & 1 \\
\hline \multicolumn{2}{|l|}{ Doctor introduction } \\
\hline Statement & 2 \\
\hline No statement & 1 \\
\hline \multicolumn{2}{|l|}{ Records of previous diagnoses } \\
\hline Statement & 2 \\
\hline No statement & 1 \\
\hline \multicolumn{2}{|l|}{ Flow of examination } \\
\hline Statement (image and text) & 3 \\
\hline Statement (only text) & 2 \\
\hline No statement & 1 \\
\hline \multicolumn{2}{|l|}{ Precautions } \\
\hline Statement & 2 \\
\hline No statement & 1 \\
\hline \multicolumn{2}{|l|}{ Terminology } \\
\hline Statement (including meaning of the term) & 2 \\
\hline Statement & 1 \\
\hline
\end{tabular}

Fourth, we converted the extracted access log into behavioral data. These behavioral data show whether each visitor browsed each page. After calculating CVR, these data were applied to the Bayesian network.

\section{Browsing Models}

Behavioral models were built based on the Bayesian network model, using BAYOLINK version 7.0.1. A Bayesian network is a probabilistic model that expresses the qualitative dependence among multiple random variables using a graph structure and expresses the quantitative relationship between individual variables based on their conditional probability. Variables are nodes, and a linked node is referred to as a "child node," and a link source node is referred to as a "parent node," as shown in Figure 4. In addition, Bayesian network can be used to determine the probability distributions of child node by observing the parent node. When using statistical models in marketing, it is 
crucial to determine whether the model is useful for decision making. Bayesian networks can express relationships between explanatory variables and even model the entire structure [23]. Although previous studies on predicting website-browsing behavior used Markov models and n-grams, such approaches were based on the premise that recent page access records have a significant influence on future page accesses [24,25]. In our models, the input value was binary for the browsing or nonbrowsing of each page for the visitors based on the premise of prior research. In other words, whether the page was browsed was represented as a node of the network. To determine the structure of the network and the parameters, we adopted Akaike's information criterion as the standard for selecting the models and the greedy search algorithm as the standard for deciding on the construction of the models. Their criterion shows adaptability to data and simplicity. The greedy search algorithm is a method of dividing the problem element into a plurality of partial problems, independently evaluating each parent combination with the highest evaluation value. In this study, all nodes were designated as parent node candidates. In addition, to show the models briefly, we built each of the models by setting pages with a small number of views as "Other pages." In our models, all the variables were binary and indicated whether browsing was performed. The joint probability indicates the probability of an arbitrary behavior being observed, and the conditional probability distribution indicates the distribution of the browsing status of the target pages considering that of a certain page. Therefore, our models show the cause-and-effect relationship between the browsing pages of the target visitor. For example, in a model in which the child node is the treatment page and the parent node is the department page, we interpret this to mean that the browsing probability for the treatment page is affected by the browsing probability for the department page. A method was then necessary to judge the strength of the influence.

Figure 4. Bayesian network outline.

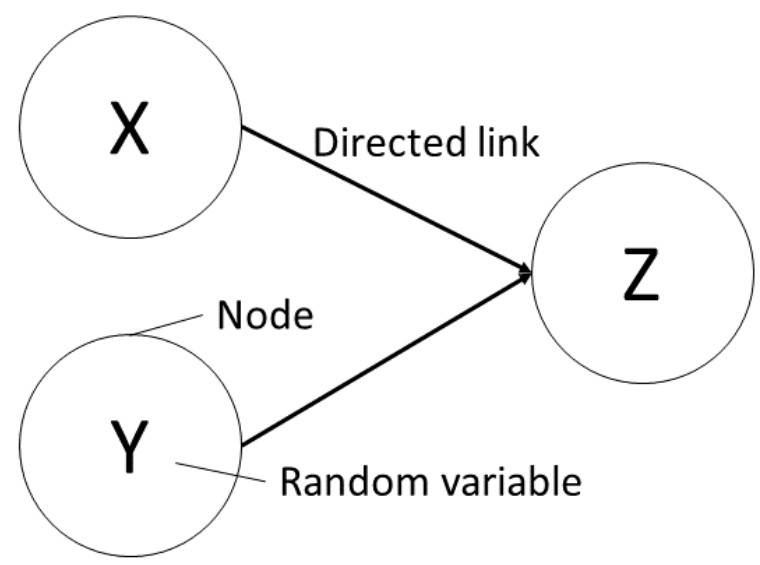

After structuring the browsing model, the sensitivity analysis was performed to determine the influence of other variables in the model on any variable and searched for pages that affected the browsing probability of the RP using mutual information. Mutual information content represents a measure of the independence of 2 random variables. Referring to the results of the sensitivity analysis, hypothetical experiments called a probability inference were conducted to determine the probability distribution of any other variable when observing certain variables and predicted the resulting variable, that is, the browsing probability of the RP.

Finally, some improvements were discussed to increase the browsing probability of the RP and meet the needs indicated from the models.

\section{Results}

\section{Traffic Summary of the Target Website}

There were 2,521,279 sessions during the study period, as presented in Table 3. Access to the department pages was concentrated next to the TOP page, as listed in Table 4. After data extraction, a behavior analysis was conducted for a total of 90 sessions, including 35 sessions for the radiotherapy interest group, 35 sessions for the nuclear medicine examination interest group, and 20 sessions for the radiological diagnosis interest group. The CVR for the 3 groups is presented in Table 5. In our study, $74 \%$ (67/90) of the targets could reach the RP.

Table 3. Access during the study period.

\begin{tabular}{lc}
\hline Indication & Values \\
\hline Page views, $\mathrm{n}$ & $2,521,279$ \\
Sessions, $\mathrm{n}$ & 663,213 \\
Users, $\mathrm{n}$ & 381,307 \\
Average pages viewed per sessions & 3.8 \\
Average session time (second) & 146 \\
\hline
\end{tabular}


Table 4. Access rate of main pages and radiology-related pages.

\begin{tabular}{ll}
\hline Page title & Page views, $\mathrm{n}(\%)$ \\
\hline TOP & $362,785(14.39)$ \\
Department Navigation & $187,558(7.44)$ \\
Medical Department Navigation & $153,454(6.09)$ \\
Department and Center Navigation & $123,462(4.90)$ \\
Access & $99,806(3.96)$ \\
Center Navigation & $28,190(1.12)$ \\
Radiotherapy Department & $7757(0.31)$ \\
Radiological Diagnosis Department & $4839(0.19)$ \\
Nuclear Medicine Examination Department & $4651(0.18)$ \\
Examination and Treatment & $2407(0.10)$ \\
\hline
\end{tabular}

Table 5. Accessibility to request pages in each model.

\begin{tabular}{|c|c|c|c|c|c|}
\hline \multirow[t]{2}{*}{ Group } & \multicolumn{5}{|l|}{$\operatorname{CVR}^{\mathrm{a}}(\%)$} \\
\hline & $\mathrm{RP}^{\mathrm{b}} 1(\%)$ & $\mathrm{RP} 2(\%)$ & RP3 (\%) & RP4 (\%) & Total $(\%)$ \\
\hline Radiotherapy & 2.9 & 80 & $-^{c}$ & - & 80 \\
\hline Nuclear medicine examination & 2.9 & 31 & 9.0 & 57 & 83 \\
\hline Radiological diagnosis & 0 & 45 & 5.0 & - & 50 \\
\hline
\end{tabular}

${ }^{\mathrm{a} C V R}$ : conversion rate.

${ }^{\mathrm{b}} \mathrm{RP}$ : request page.

${ }^{\mathrm{c}}$ The lower rank RP in certain groups was not set in our judgement. Therefore, certain CVRs were treated as not applicable.

\section{Radiotherapy Interest Group}

The model described in Figure 5 was structured using 35 sessions from the learning data. The browsing of RP2, the "Radiotherapy Department page," was affected by the browsing of the Proton Therapy News page, which affected the browsing of the radiology-related department and Medical Expenses pages. The results of the sensitivity analysis are illustrated in Figure 6. The mutual information volume of the Proton Therapy
News page was the largest, indicating that browsing this page had the greatest effect on the browsing of RP2. Based on the results of the sensitivity analysis, we calculated the change in the browsing probability of RP2 owing to browsing or nonbrowsing of the pages based on a probability inference, as shown in Figure 7. When the target visitor browses the Radiological Diagnosis Department page, the probability of RP2 increased by $17 \%$ from the prior probability. 
Figure 5. Radiotherapy model.

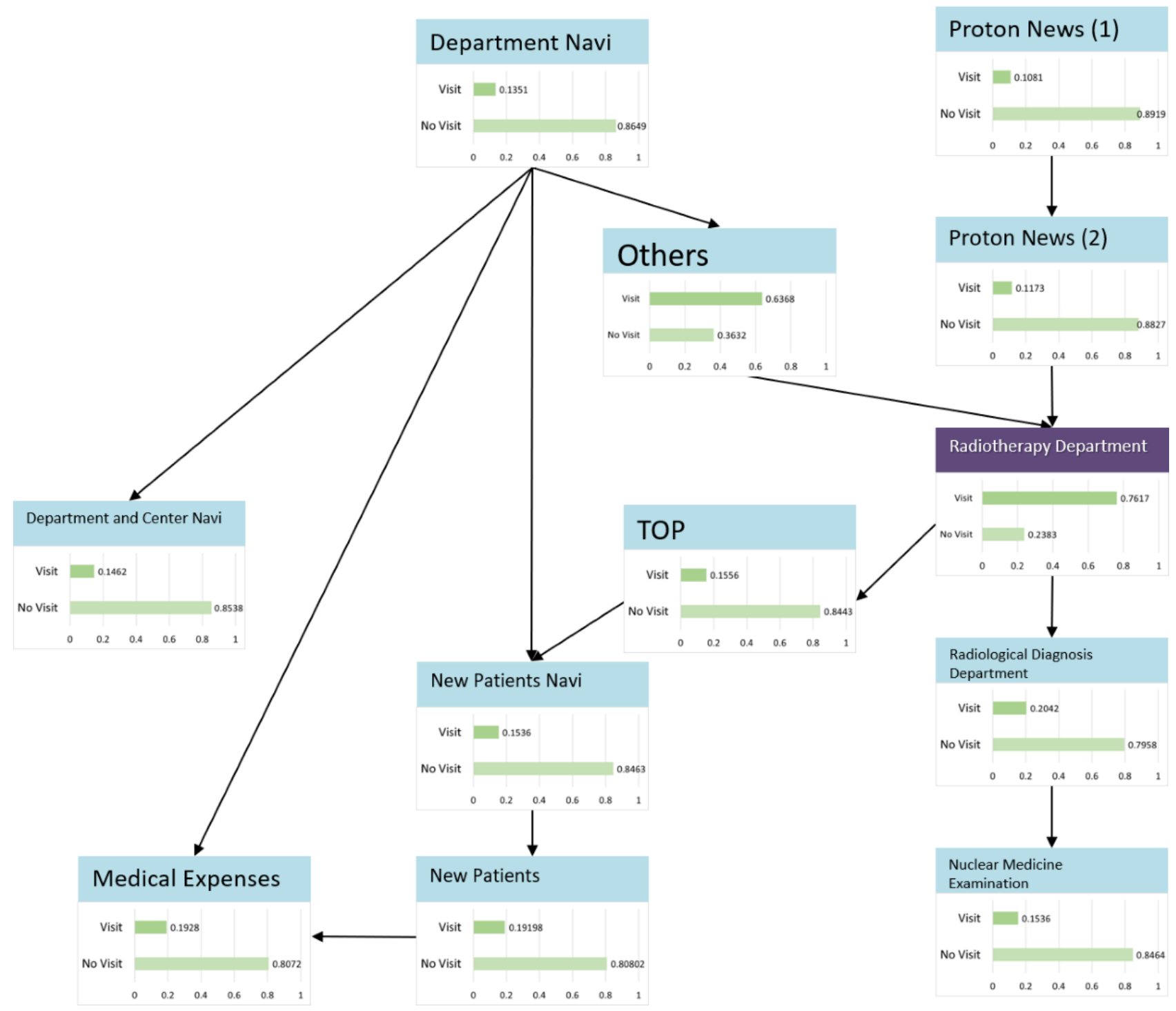

Figure 6. Sensitivity analysis (radiotherapy interest group).

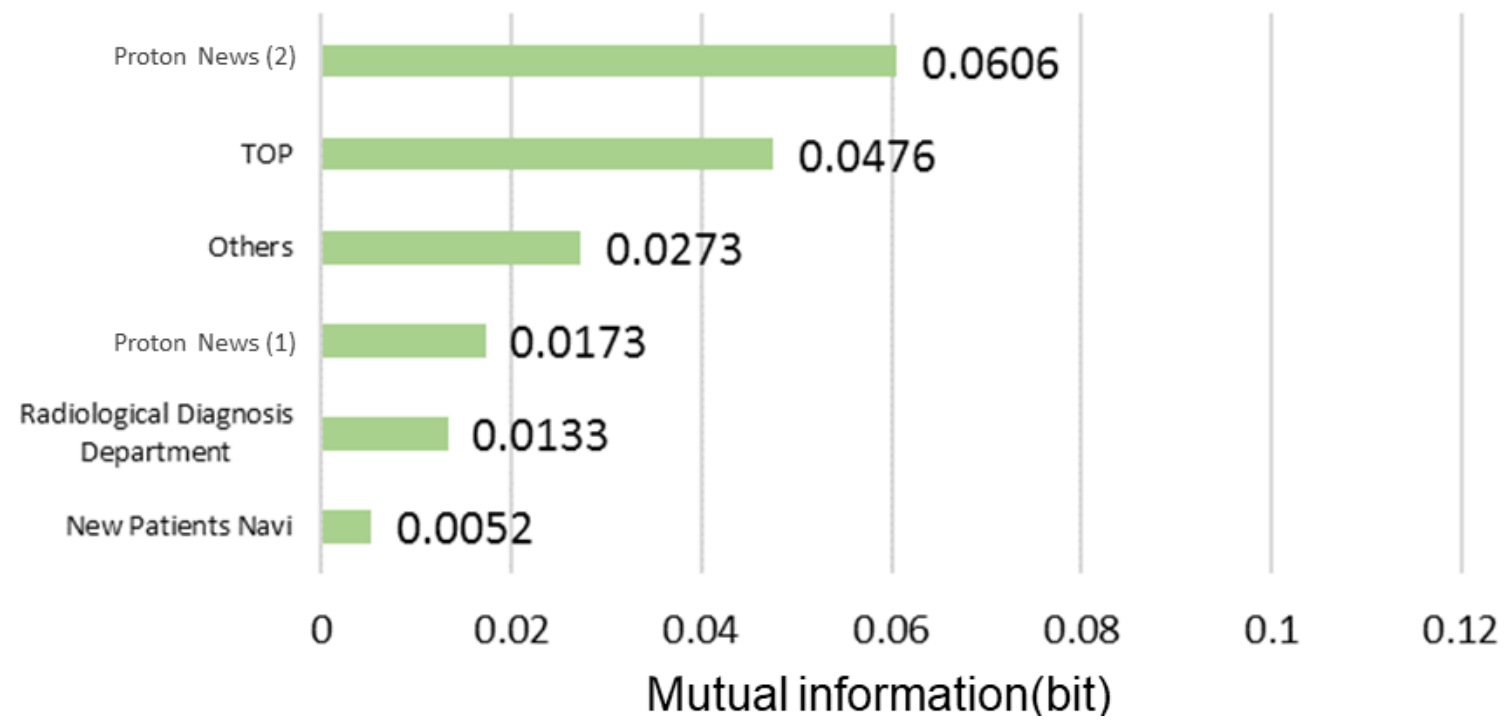


Figure 7. Probability inference (radiotherapy interest group, Radiotherapy Department page).

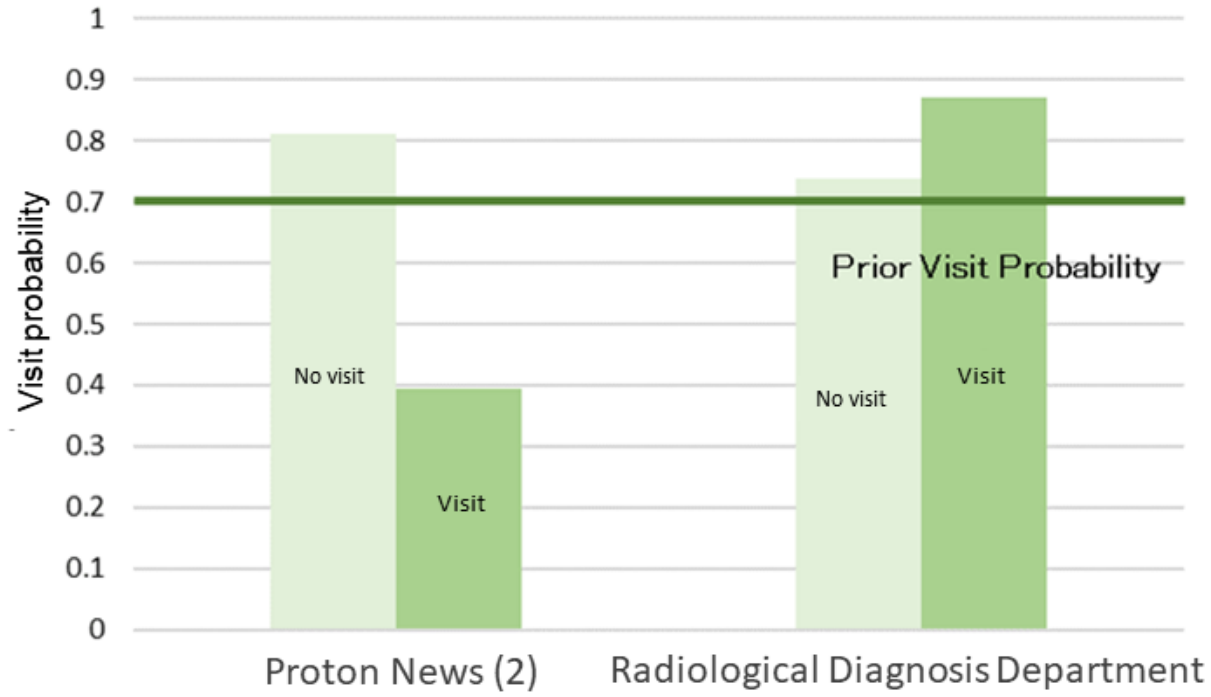

\section{Nuclear Medicine Examination Interest Group}

The model, as described in Figure 8, was structured using 35 sessions from the learning data. Browsing of the RP2 "Nuclear Medicine Department page" was affected by the browsing of RP4 "PRT-CT and Nuclear Medicine Examination" and was related to the browsing of the reservation and the medical staff pages. The results of the sensitivity analysis are shown in Figure
9. The interaction between the browsing of RP2 and that of RP4 was also demonstrated. We then calculated the change in the browsing probability of RP2 and RP3 owing to the browsing or nonbrowsing of the pages, as depicted in Figures 10 and 11. The browsing probability of RP2 increased when browsing the Medical Staff page. When the target visitors browsed the FAQ page, the browsing probability of RP3 increased by $15 \%$ from the prior probability. 
Figure 8. Nuclear medicine examination model.

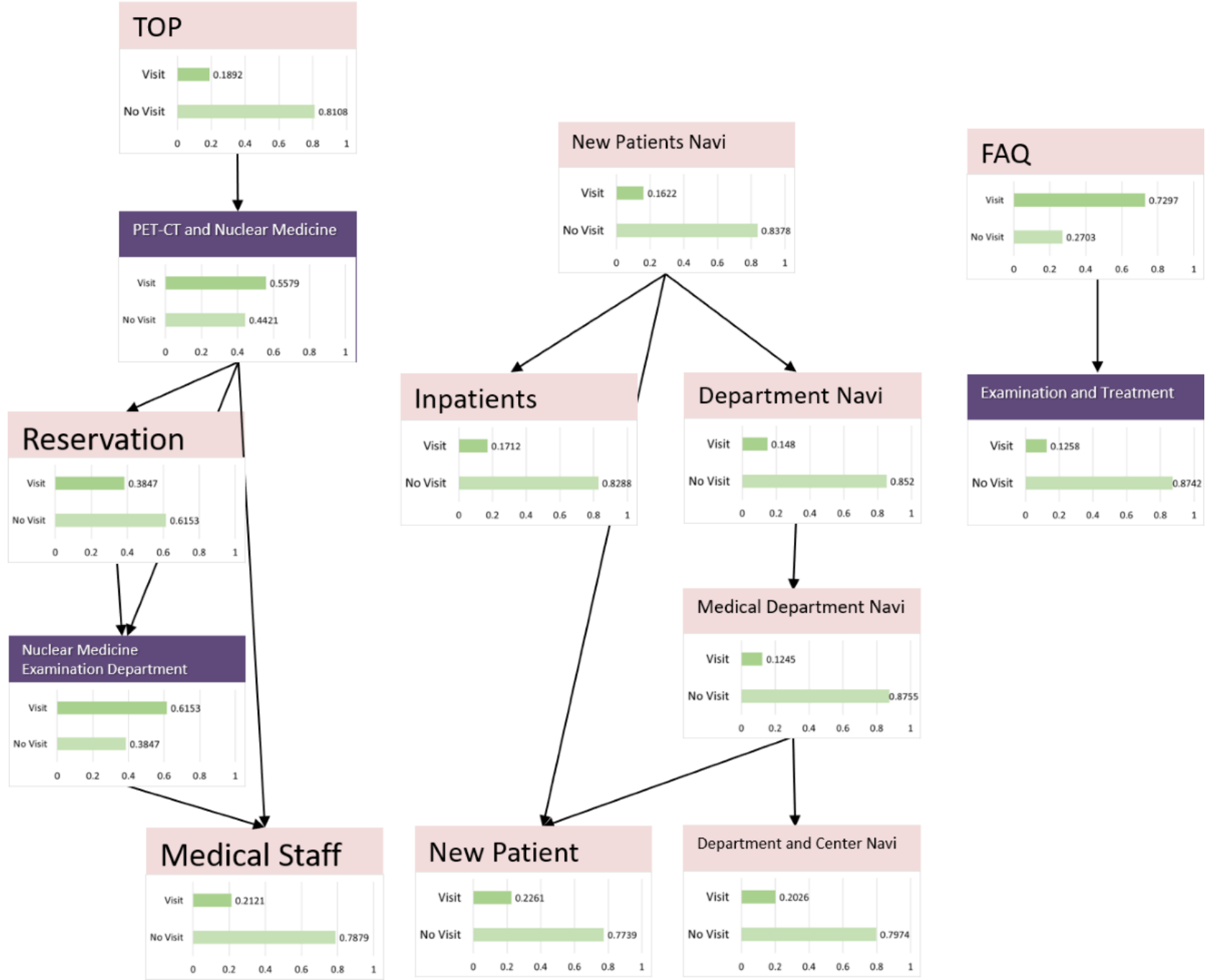


Figure 9. Sensitivity analysis (nuclear medicine examination interest group). PET-CT: positron emission tomography-computed tomography.

\section{a) Nuclear Medicine Examination Department page}

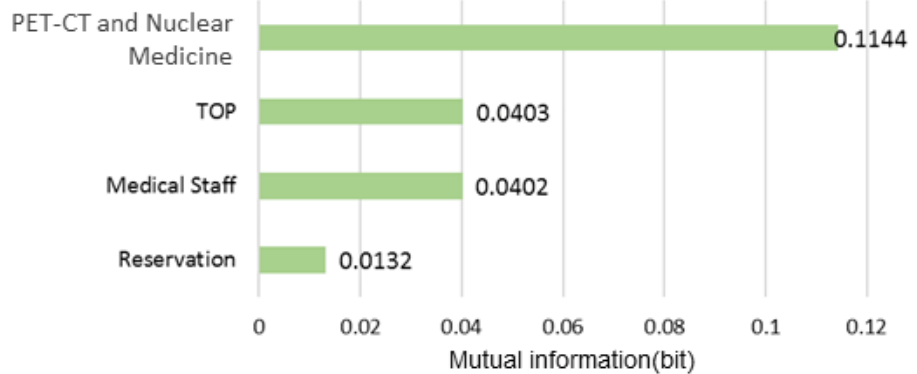

b) PET-CT and Nuclear Medicine page

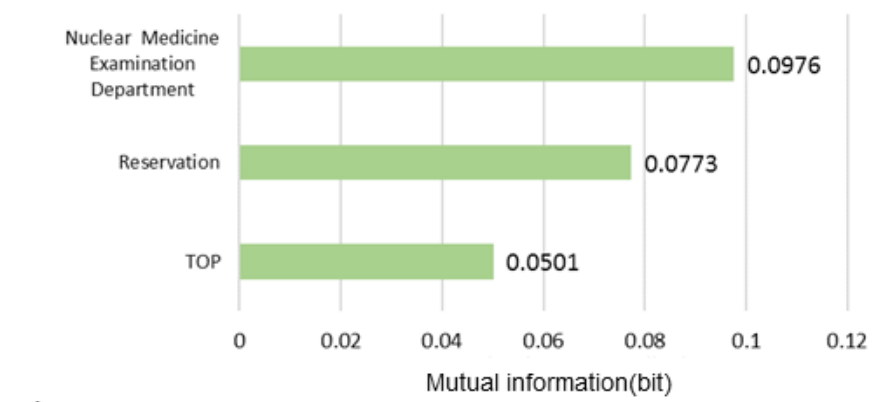

C)Examination and Treatment page

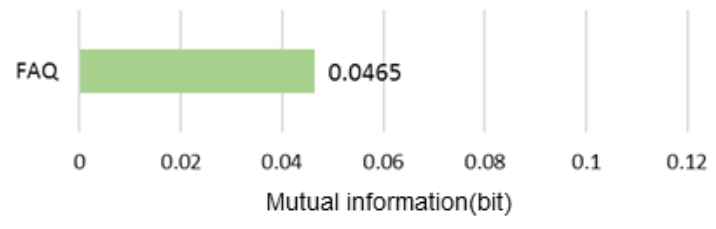

Figure 10. Probability inference (nuclear medicine examination interest group, Nuclear Medicine Examination Department page). PET-CT: positron emission tomography-computed tomography.

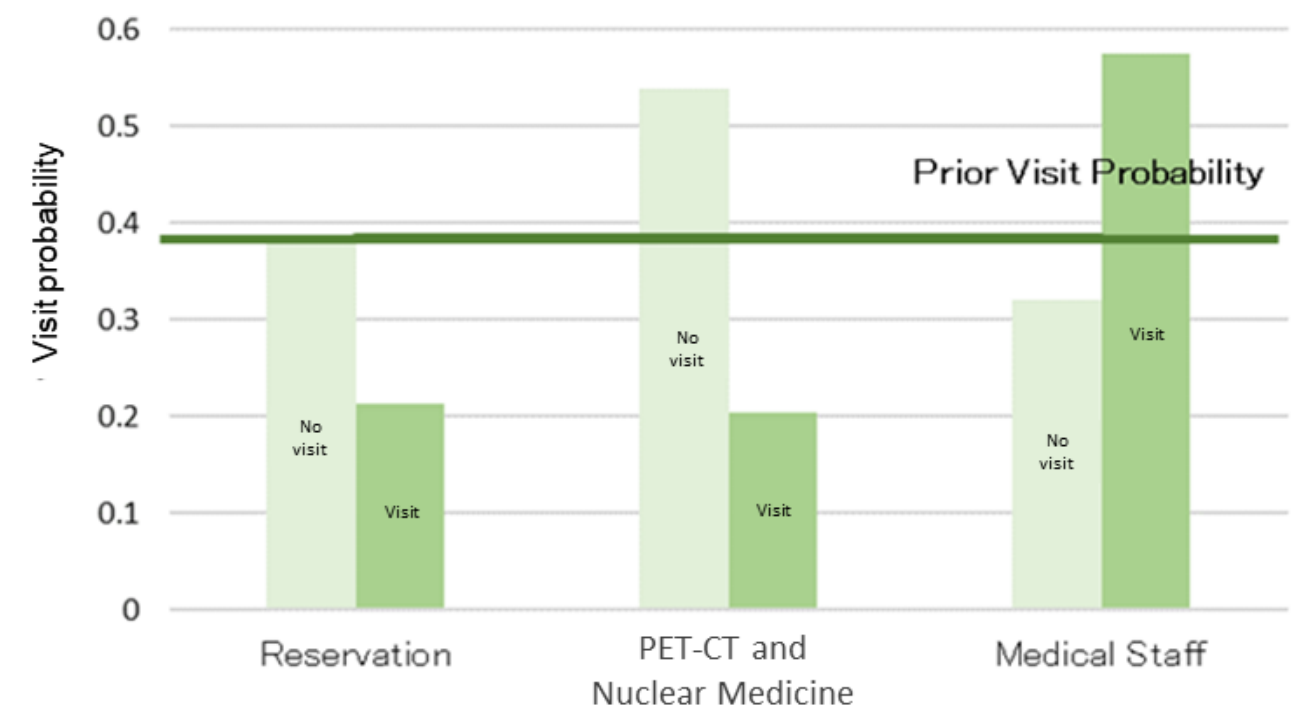


Figure 11. Probability inference (nuclear medicine examination interest group, Examination and Treatment page).

0.3

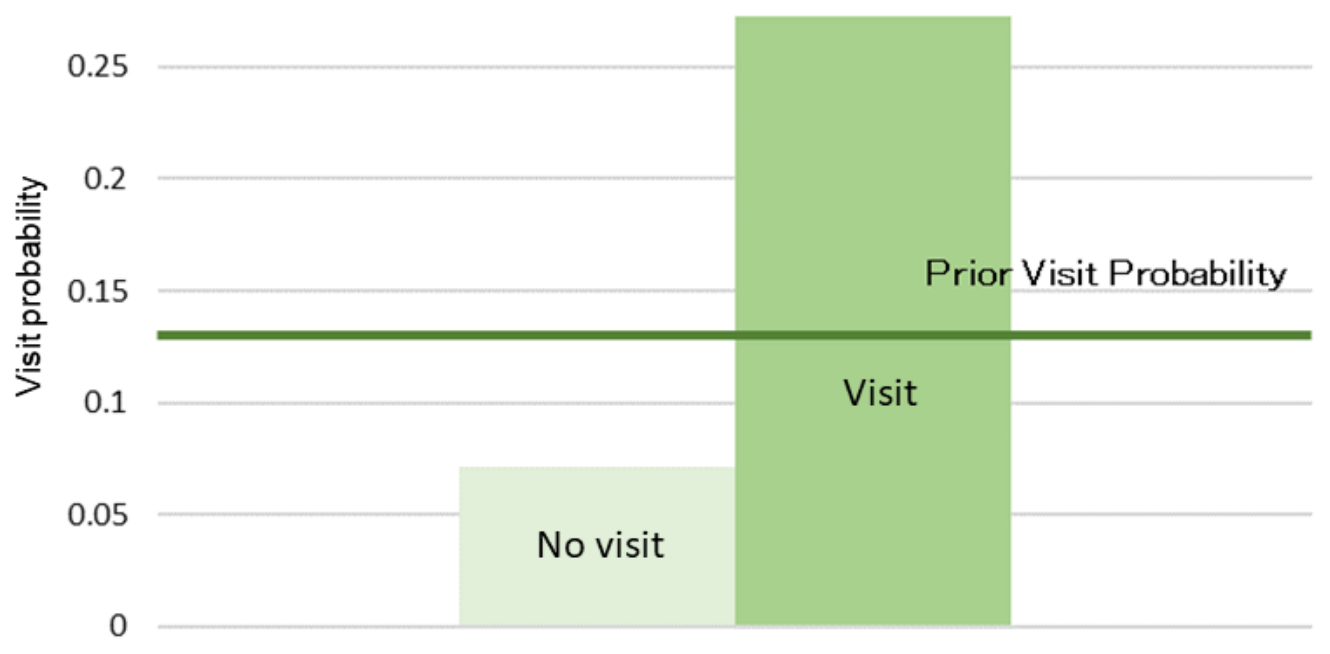

$\mathrm{FAQ}$

\section{Radiological Diagnosis Interest Group}

The model described in Figure 12 was structured using 20 sessions from the learning data. The browsing of the RP2 "Radiological Diagnosis Department page" affected the browsing of the Radiotherapy Department and related department pages, such as Orthopedics. The results of the sensitivity analysis are shown in Figure 13. Browsing of the
Radiotherapy Department page had the greatest impact on RP2 viewing. We then calculated the change in the browsing probability of RP2 owing to the browsing or nonbrowsing of the Radiotherapy Department page, as shown in Figure 14. When the target visitors browsed the Radiotherapy Department page, the probability of RP2 increased by $35 \%$ from the prior probability. 
Figure 12. Radiological diagnosis model. PET-CT: positron emission tomography-computed tomography.

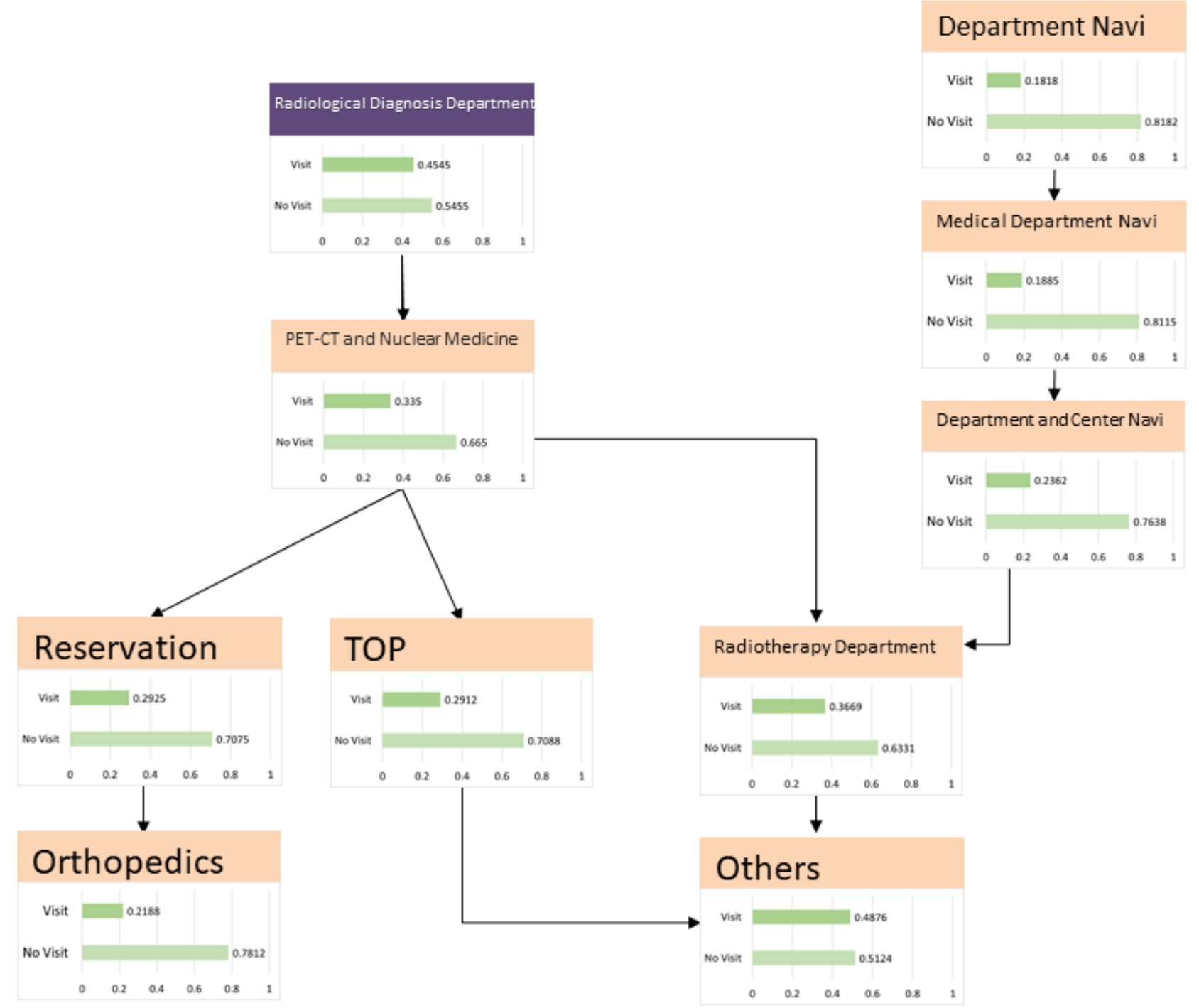

Figure 13. Sensitivity analysis (radiological diagnosis interest group).

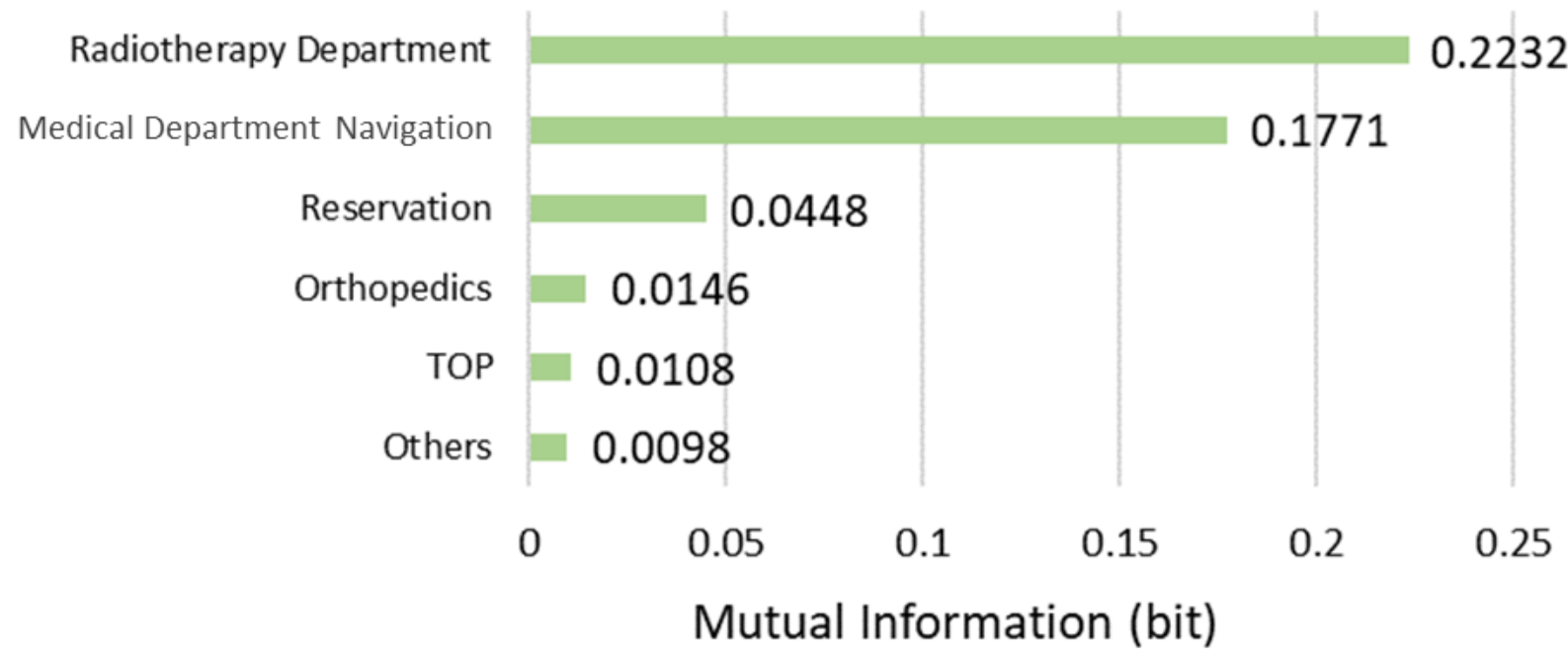


Figure 14. Probability inference (radiological diagnosis interest group, Radiological Diagnosis page).

0.3

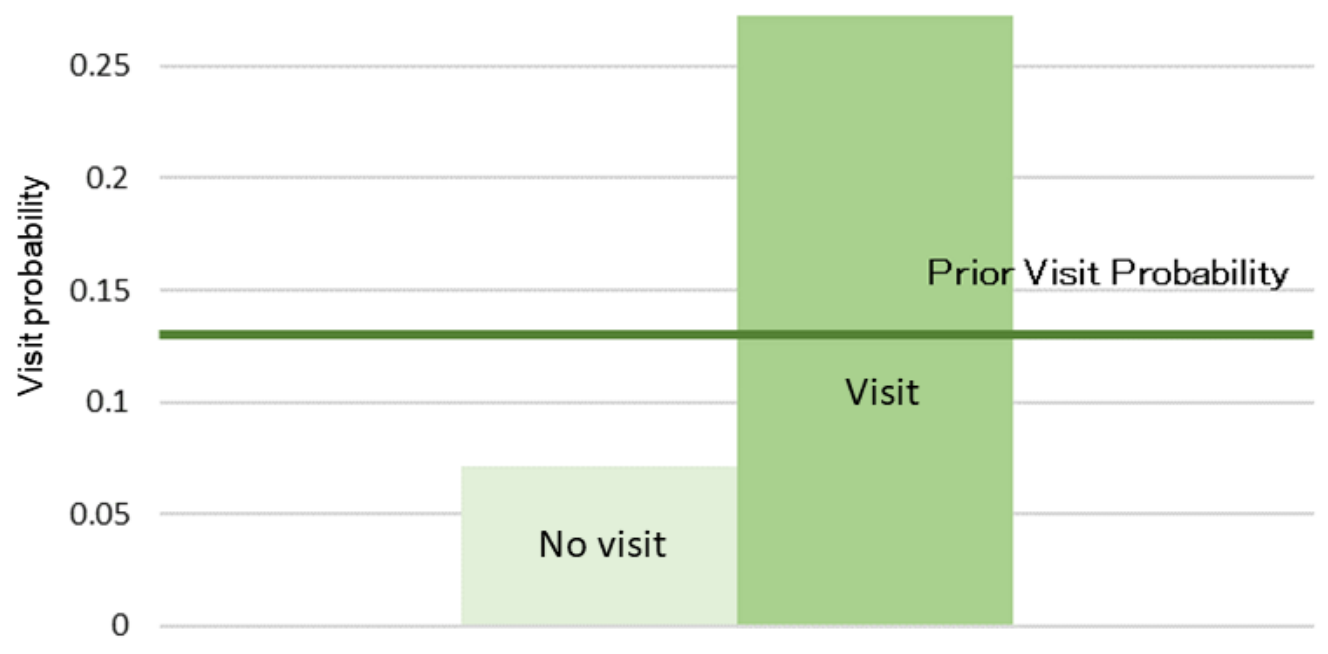

$\mathrm{FAQ}$

\section{Discussion}

The number of visiting sessions on the Hokkaido University Hospital website is over 650,000 per year. This number is comparable to the number of actual patients to the hospital annually (approximately 740,000 in 2015) and indicates that the website plays a key role as an information provider for many individuals.

Only 2\% (2/90) of the target visitors could reach the Radiology Center page (RP1), which describes its inspection information. There are 3 possible reasons for this finding: browsing behavior (the visitor started with the department pages, not the Center page), the visitor could not distinguish the Radiology Center pages from the radiology-related department pages that describe the department information, and that there are some pages for which we could not obtain the data access log. In total, 2 plans were considered for improving the browsing probability of RP1: linking the radiology-related department pages and the Radiology Center page, and summarizing radiology-related information on the website rather than posting according to the hospital's organizational structure.

According to the radiotherapy model, when browsing the Proton Therapy News page, the browsing probability of the RP2 "Radiotherapy Department page" decreased. Therefore, we found that interest in radiotherapy and interest in news differed from one another, or that there was no conductor design. In addition, because the child node of the Radiotherapy Department page had the pages of new patients and medical expenses pages, patients who receive radiation treatment tend to seek information on receiving medical treatment such as medical expenses owing to the high price of proton therapy [26]. In a questionnaire survey of medical radiological specialists, it was reported that a certain number of technicians were asked about the cost of radiotherapy in treating patients receiving cancer radiotherapy [27].

In the nuclear medicine examination interest group, the browsing probability of the FAQ page was higher than that of the other 2 groups. In addition, as a result of the probability inference, a positive relationship was found between browsing the FAQ page and the Examination and Treatment page. Because the FAQ page is generally used for posting information on exceptional cases such as product guidelines and specific topics [28], target visitors may be concerned about specialized information, except for the content of the RP. From Figure 10, the browsing probability of the RP2 "Nuclear Medicine Examination Department page" was higher than the prior probability when browsing the Medical Staff page. Because neither of these pages were designed with a link that allows direct access, it is mainly the medical staff that browse them.

In the radiological diagnosis model, the RP2 "Radiological Diagnosis Department page" contained child nodes, such as the Orthopedics Department page, indicating that visitors are interested in the contents of the departments they are associated with. Table 6 presents the proportion of radiological diagnosis conducted at Hokkaido University Hospital, with the proportion of "bone/soft" being the second highest after "respiratory organs." Therefore, the site design was considered, linking radiology-related department pages with their related department pages and redesigning the website considering the flow of treatment and inspection. 
Table 6. Number of radiological examinations at Hokkaido University Hospital (April 2018 to March 2019).

\begin{tabular}{ll}
\hline Classification & Inspections, $\mathrm{n}(\%)$ \\
\hline Respiratory & $53,322(41.9)$ \\
Bone and soft part & $30,230(23.8)$ \\
Digestive organ & $27,141(21.3)$ \\
Tooth & $16,685(13.1)$ \\
Others & $18(0)$ \\
\hline
\end{tabular}

From the results of the probability inference, the browsing probability of the RP2 "Radiological Diagnosis Department page" was higher than the prior probability when browsing the Radiotherapy Department page. According to these results, visitors interested in radiology-related departments would access RP2, which indicates that CVR can be improved by linking radiology-related departments. The percentage of visitors who browsed the RP3 "Examination and Treatment page" was small. This is thought to be due to the low interest of the target visitor or their inability to reach the page. In the latter case, we suggest that CVR can be increased by linking to the "Radiology Department page," where the targets have a high percentage of browsing.

Table 7 presents the site design proposals to increase the CVR, as examined from the results. Thus, this research concluded that our method is effective in improving the provision of information because improving the quality of decision making is crucial in data analytics, as exemplified through business intelligence tools [29]. The proposed method can be applied to departments other than radiology-related areas.

Table 7. Proposals for site design to meet the needs of visitors seeking radiology-related information.

\begin{tabular}{llll}
\hline $\mathrm{RP}^{\mathrm{a}}$ & Improvement 1 & Improvement 2 & Improvement 3
\end{tabular}

\section{A. Improve $\mathrm{CVR}^{\mathrm{b}}$ of radiotherapy interest group}

RP1: Radiology Center page

Link the Radiology Center page and radiology-related department pages

RP2: Radiotherapy Department page

Link the Radiotherapy Department page and Radiological Diagnosis Department page

\section{B. Improve CVR of nuclear medicine examination interest group}

RP1: Radiology Center page

RP2: Nuclear Medicine Examination Department page

RP3: Examination and Treatment page

RP4: PRT-CT ${ }^{\mathrm{d}}$ and Nuclear Medicine Examination page
Same as above

Link the Nuclear Medicine Examination Department page and the Medical Staff page

Review of posted contents on the Examination and Treatment page

Link the PRT-CT and Nuclear Medicine Examination page and the Nuclear Medicine Examination Department page

\section{Improve CVR of radiological diagnosis interest group}

\author{
RP1: Radiology Center page \\ RP2: Radiological Diagnosis Department page
}

RP3: Examination and Treatment page
Same as above

Link Radiological Diagnosis Department page and the Radiotherapy Department page

Link the Radiological Diagnosis Department page and the Examination and Treatment page

\footnotetext{
${ }^{\mathrm{a}} \mathrm{RP}$ : request page.

${ }^{\mathrm{b}} \mathrm{CVR}$ : conversion rate.

${ }^{\mathrm{c}}$ The certain CVRs were treated as not applicable in our behavioral analysis.

${ }^{\mathrm{d}}$ PRT-CT: positron emission tomography-computed tomography.
}

Link the Radiology Center page and pages such as the New $\mathrm{Pa}$ tients page and Re-examination page

Link the Radiotherapy Department page and the Medical Expenses page

Same as above

Same as above

$-$

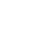

Set tracking

code

c

$$
\text { (1) }
$$

Same as above

Same as above

Link the Radiological Diagnosis page and the Orthopedics page
-

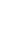




\section{Limitations}

One of the limitations of this study is the low accuracy of the models applied. The number of samples (20-35 sessions) used to build the models was small compared with the actual usership for Hokkaido University Hospital's website. Owing to the recent shift to Secure Sockets Layer for use in search engines, the sample size has remained limited. Future studies should substitute search keywords. Furthermore, some data may have been missing because there were some pages set with the no web tracking code in Google Analytics. By increasing the sample size, factors such as browsing time can be incorporated into the model, improving the prediction accuracy for the probability distribution of each page. However, the effects of the visitor's interest on each page regarding factors such as the browsing time and browsing devices for hospital websites are still unknown. Therefore, it is necessary to clarify the effects of the browsing factors before modeling.

As another limitation, we were unable to verify the accuracy of the proposed model compared to other approaches. To evaluate our model, we need to accurately set the web tracking code and extract data without using retrieval keywords because we have obtained few retrieval data in recent years.

Third, the RP we set during the page-evaluation phase is uncertain. Thus, setting an RP objectively to obtain information by means of questionnaires to accurately understand visitor needs will be an issue in the future. Similarly, it will be possible to evaluate pages suitable for each visitor by clarifying the above relationship between visitor interests for each page and access indicators such as the browsing time. In recent years, Japan has been rapidly aging, and older adults are using hospital websites. However, previous studies have reported that age-related deterioration in visual acuity and changes in color vision affect the use of older adults to use such websites [30,31]. Therefore, we hope that the factors affecting CVR differ between older adults and young adults. In the future, we would like to consider improving the CVR by modeling the categorization of young and older adults.

\section{Conclusions}

This study structured 3 browsing models, each based on specific patient needs: radiotherapy, nuclear medicine examination, and radiological diagnosis. A total of 74\% (67/90) of the target visitors could reach their requested page, but only $2 \%(2 / 90)$ could reach the inspection information page owing to the site structure. Furthermore, for the radiological diagnosis interest group, browsing of the "Radiological Diagnosis Department page" affected the browsing of the related department pages, such as Orthopedics.

Plans were considered for improving the browsing probability of the inspection information page such as summarizing radiology-related information on the website rather than posting according to the hospital's organizational structure. Thus, our method has the potential to increase the probability of delivering the desired information to the users. In the future, we plan to improve the accuracy of the models by using a large number of samples. We believe that an increase in the number of subjects will reveal the characteristics of the browsing scenario in more detail.

We built models with the objective of improving the provisioning of radiology-related information; however, because the structure of a hospital website is not unique, we hope to apply the proposed method to other hospitals. It is expected that the provisioning of information on hospital websites will be improved using this approach.

\section{Conflicts of Interest}

None declared.

\section{Multimedia Appendix 1}

Radiation-related search keyword.

[PDF File (Adobe PDF File), 162 KB-Multimedia Appendix 1]

\section{References}

1. The Ministry of Health, Labor and Welfare. URL: https://www.mhlw.go.jp/toukei/saikin/hw/kanja/17/dl/01.pdf [accessed 2020-10-22]

2. Tani Y. Important factors in improving the management of small and medium-sized medical corporation hospitals. Management Studies (in Japanese) 2017;01:1. [doi: 10.24472/abjaba.88.0 F1-1]

3. Nakayama T. Evidence-based Risk and Benefit Communication for Shared Decision Making. YAKUGAKU ZASSHI 2018;138(3):331-334. [doi: 10.1248/yakushi.17-00185-5]

4. Treatment behavior survey (Japanese). The Ministry of Health, Labor and Welfare. 2017. URL: https://www.mhlw.go.jp/ toukei/saikin/hw/jyuryo/17/dl/kakutei-kekka-gaiyo.pdf [accessed 2020-10-22]

5. Telecommunications usage trend survey (in Japanese). The Ministry of Internal AffairsCommunications. 2018. URL: https:/ /www.soumu.go.jp/johotsusintokei/statistics/data/190531 1.pdf [accessed 2020-10-22]

6. Media fixed-point survey. Hakuhodo Inc. 2019. URL: https://mekanken.com/cms/wp-content/uploads/2019/05/ 167f92d09ab7cc5c8f1c38af84b23107.pdf [accessed 2020-10-22]

7. Survey on public opinion on medical care (in Japanese). National Federation of Health Insurance Societies. 2017. URL: https://www.kenporen.com/include/outline/pdf/chosa29 02.pdf [accessed 2020-10-22] 
8. Korda H, Itani Z. Harnessing social media for health promotion and behavior change. Health Promot Pract 2013;14(1):15-23. [doi: $10.1177 / 1524839911405850]$

9. Uchida T. A study from Actual Condition Survey of Public Relations Department at University Hospital in Japan. IT healthcare. 2010. URL: http://ithealthcare.jp/jnl/5.1/069.pdf [accessed 2020-10-22]

10. Medical advertisement guideline. The Ministry of Health, Labor and Welfare. 2007. URL: https://www.mhlw.go.jp/file/ 06-Seisakujouhou-10800000-Iseikyoku/0000209841.pdf [accessed 2020-10-22]

11. Ha S, Bae S, Park S. Intelligent Marketing and Merchandising Techniques for an Internet Shopping Mall. PACIS Proceedings. 2001. URL: https://aisel.aisnet.org/pacis2001/75 [accessed 2020-10-22]

12. Montgomery AL, Smith MD. Prospects for Personalization on the Internet. Journal of Interactive Marketing 2009 May;23(2):130-137. [doi: 10.1016/j.intmar.2009.02.001]

13. Outline of the low that revises part of medical law (review of advertising regulation concerning medical care) (in Japanese). The Ministry of Health, Labor and Welfare. 2017. URL: https://www.mhlw.go.jp/file/06-Seisakujouhou-10800000-Iseikyoku/ 0000171625.pdf [accessed 2020-10-22]

14. Fujimoto S, Komukai K, Kobu S, Sugita S, Kobayashi S. The quality of website information of private-practice hospital or clinics in rehabilitation. Japanese Physical Therapy Association, . (In Japanese) 2017;44(6):456-462. [doi: 10.15063/rigaku.11332]

15. Huerta TR, Walker DM, Ford EW. An Evaluation and Ranking of Children's Hospital Websites in the United States. J Med Internet Res 2016 Aug 22;18(8):e228. [doi: 10.2196/jmir.5799] [Medline: 27549074]

16. Suzuki T, Tani Y, Ogasawara K. Behavioral Analysis of Visitors to a Medical Institution's Website Using Markov Chain Monte Carlo Methods. J Med Internet Res 2016 Jul 25;18(7):e199. [doi: 10.2196/jmir.5139]

17. Kunugita N. [Investigation of the relationship between knowledge concerning radiation and the level of anxiety toward radiation in student nurses]. J UOEH 2008 Dec 01;30(4):421-429. [doi: 10.7888/juoeh.30.421] [Medline: 19086700]

18. Association for Nuclear Technology in Medicine. URL: https://www.antm.or.jp/05 treatment/04.html [accessed 2019-12-23]

19. Okazaki R, Ootsuyama A, Abe T, Kubo T. A Questionnaire Survey about Public's Image of Radiation after the Fukushima Daiichi Nuclear Power Plant Accident. J UOEH 2012;34(1):91-105. [doi: 10.7888/juoeh.34.91]

20. Nakatsu E, Tsuji Y, Tamiya S, Sudo K. Website renewalaccess log analysis related to the opening of the new hospital. The Journal of Otaru General Hospital. 2016. URL: https://barrel.repo.nii.ac.jp/

?action=pages_view_main\&active_action=repository_view_main_item_detail\&item_id=4881\&item_no=1\&page_id=13\&block_id=135 [accessed 2020-12-09]

21. Liu H, Kešelj V. Combined mining of Web server logs and web contents for classifying user navigation patterns and predicting users' future requests. Data \& Knowledge Engineering 2007 May;61(2):304-330. [doi: 10.1016/j.datak.2006.06.001]

22. Suzuki T, Sasaki A, Hayashi K, Yagahara A, Ogasawara K. Medical information fulfillment degree of hospital website, Japan Institution of Medical Informatics 2015. (in Japanese) 2015;35(3):133-140. [doi: 10.14948/jami.35.133]

23. Mayomi H, Yoichi M. Marketing strategy product development using Bayesian networks;. Committee on Basic Artificial Intelligence (in Japanese). 2005. URL: http://mayomi.org/research01/haga/pdf02/BN2005haga050829.pdf [accessed 2020-12-09]

24. Chen MS, Park JS, Yu P. Efficient data mining for path traversal patterns. IEEE Trans Knowl Data Eng 1998;10(2):209-221. [doi: $10.1109 / 69.683753$ ]

25. Oikonomopoulou D, Rigou M, Sirmakessis S, Tsakalidis A. Full-Coverage Web Prediction based on Web Usage Mining and Site Topology. 2004 Presented at: IEEE/WIC/ACM Int Conf Web Intell .?719; 2004; Thessaloniki Greece p. 716. [doi: 10.1109/wi.2004.10144]

26. Iwata H, Ishikawa H, Takagi M, Okimoto T, Murayama S, Akimoto T, et al. Long-term outcomes of proton therapy for prostate cancer in Japan: a multi-institutional survey of the Japanese Radiation Oncology Study Group. Cancer Med 2018 Feb 14;7(3):677-689. [doi: 10.1002/cam4.1350]

27. Mariko K. Survey on radiological technologists? interactions with patients undergoing cancer radiotherapy(in Japanese). The Journal of Japan Academy of Health Sciences. 2015. URL: https://www.health-sciences.jp/journal/backnumber/017 04. pdf\#page=19 [accessed 2020-12-09]

28. Romero M, Moreo A, Castro J. A cloud of FAQ: A highly-precise FAQ retrieval system for the Web 2.0. Knowledge-Based Systems 2013 Sep;49:81-96. [doi: 10.1016/j.knosys.2013.04.019]

29. Wang C. A novel approach to conduct the importance-satisfaction analysis for acquiring typical user groups in business-intelligence systems. Computers in Human Behavior 2016 Jan;54:673-681. [doi: 10.1016/j.chb.2015.08.014]

30. Saito D, Saito K, Notomi K, Saito M. Comparison of standard link color visibility between young adults and elderly adults. Electron Comm Jpn 2008 Jul;91(7):41-47. [doi: 10.1002/ecj.10126]

31. Sri KZ. Research-derived web design guidelines for older people. 2005 Presented at: the 7th international ACM SIGACCESS conference on Computersaccessibility (Assets '05). Association for Computing Machinery, New York, NY, USA. ;129?135; 2005; New York, NY, USA. [doi: 10.1145/1090785.1090810] 


\section{Abbreviations}

CVR: conversion rate

RP: request page

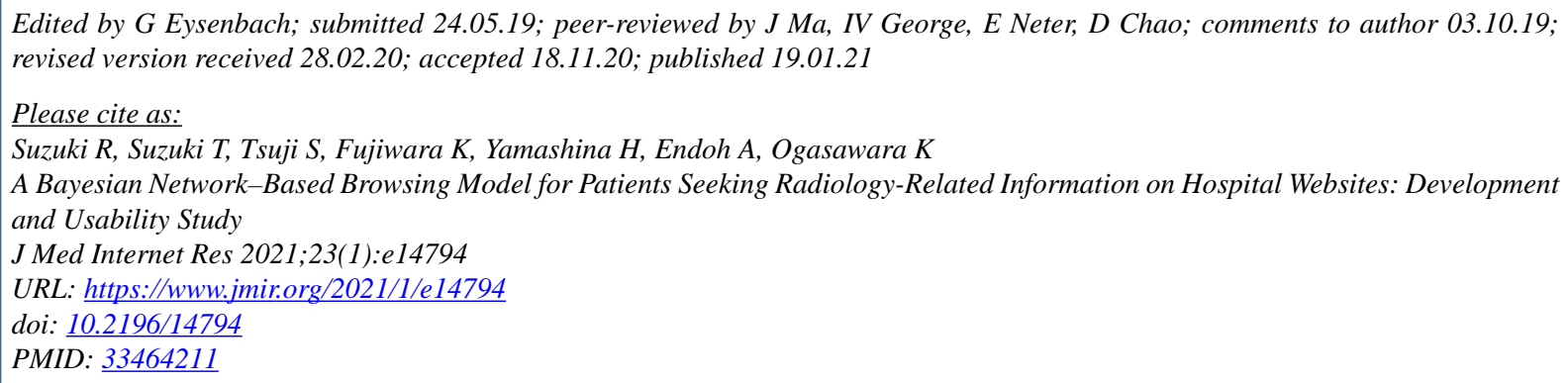

(CRyusuke Suzuki, Teppei Suzuki, Shintaro Tsuji, Kensuke Fujiwara, Hiroko Yamashina, Akira Endoh, Katsuhiko Ogasawara. Originally published in the Journal of Medical Internet Research (http://www.jmir.org), 19.01.2021. This is an open-access article distributed under the terms of the Creative Commons Attribution License (https://creativecommons.org/licenses/by/4.0/), which permits unrestricted use, distribution, and reproduction in any medium, provided the original work, first published in the Journal of Medical Internet Research, is properly cited. The complete bibliographic information, a link to the original publication on http://www.jmir.org/, as well as this copyright and license information must be included. 